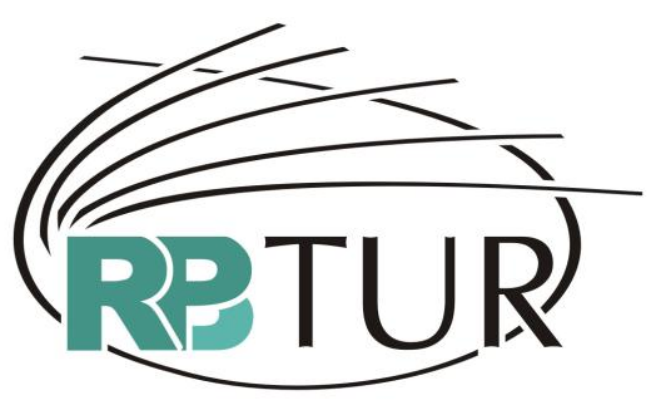

REVISTA BRASILEIRA DE PESQUISA EM TURISMO

\title{
PROJETO DE MONITORIA TURISMO E REVITALIZAÇÃO: CONTRIBUIÇÕES DE PLANEJAMENTO E MARKETING PARA O CENTRO HISTÓRICO DE JOÃO PESSOA (PARAÍBA, BRASIL)
}

\author{
TOURISM AND REVITALIZATION ACADEMIC PROJECT: \\ PLANNING AND MARKETING ISUES FOR THE HISTORIC CITY \\ IN JOÃO PESSOA (PARAÍBA, BRASIL)
}

\begin{abstract}
PROYECTO TURISMO Y REVITALIZACIÓN: CONTRIBUCIONES DE LA PLANIFICACIÓN Y EL MARKETING PARA EL CENTRO HISTÓRICO DE JOÃO PESSOA (PARAÍBA, BRASIL)
\end{abstract}

Ana Valéria Endres ${ }^{1}$

André Luiz Piva de Carvalho ${ }^{2}$

\begin{abstract}
Resumo: Relato de uma experiência realizada no Curso de Turismo da Universidade Federal da Paraíba, integrando as disciplinas do curso num trabalho de revitalização do centro histórico de João Pessoa. Descrevem-se o curso, a cidade, as comunidades envolvidas e a metodologia utilizada para a integração das disciplinas entre si e com a comunidade. Conclui-se que o estudo foi relevante para a formação de um bacharel em turismo consciente e responsável, capaz de ser agente do desenvolvimento sustentável do turismo regional, sempre a favor da população local.

Palavras chave: Ensino Superior em Turismo. Curso de Turismo da UFPA. Projeto de Monitoria. Planejamento e Marketing. Revitalização do Centro Histórico. João Pessoa. Paraíba. Brasil.

${ }^{1}$ Doutoranda em Sociologia Política pela Universidade Federal de Santa Catarina, Mestre em Planejamento do Desenvolvimento, Especialista em Desenvolvimento de Áreas Amazônicas e em Ecoturismo, e Bacharel em Turismo pela Universidade Federal do Pará. Professora do curso de Turismo da Universidade Federal da Paraíba (Paraíba, Brasil). Email: valendres@hotmail.com

${ }^{2}$ Doutor em Cultura e Sociedade pela Universidade Federal da Bahia e Mestre em Ciências da Comunicação pela Universidade de São Paulo; Especialista em Metodologias do Ensino Superior (Unimar) e Metodologias da Comunicação (UFPB); Graduado em Direito pela Faculdade de Direito da Alta Paulista, e em Jornalismo e Relações Publicas pela Faculdades Integradas Alcântara Machado (Brasil). Docente e coordenador do curso de Turismo da Universidade Federal da Paraíba (Paraíba, Brasil). Email: profpiva@uol.com.br
\end{abstract}


Abstract: The article registers an experience by the Tourism Program at Universidade Federal da Paraíba, through the integration of courses in a revitalization project at João Pessoa historic center. The program is described as well as the city, communities, and methodology to achieve integration between courses and community. The conclusion was that this kind of field work is relevant for a Bachelor in Tourism to be a conscious and responsible agent for sustainable development of regional tourism regarding locals.

Keywords: Higher Education in Tourism. UFPA Tourism Program. Academic Project. Planning and Marketing. Revitalization of the historic city. João Pessoa. Paraíba. Brazil.

Resumen: El artículo retrata una experiencia realizadas por el Curso de Turismo de la Universidad Feredal de Paraíba, congregando las materias del curso en torno de la revitalización del centro histórico de João Pessoa (capital de Paraíba). Describe el funcionamiento del curso, la ciudad, las comunidades involucradas y la metodología utilizada para la integración de las materias entre sí y del proyecto con la comunidad. Concluye que el trabajo tuvo relevancia para la formación de licenciados en turismo conscientes y responsables capaces de ser agentes del desarrollo sostenido del turismo regional, siempre a favor de la población local.

Palabras clave: Curso de Turismo de la UFPA. Ayudantía. Planificación y Marketing. Revitalización del Centro Histórico. João Pessoa. Paraíba. Brasil.

\section{Introdução}

Este trabalho foi apresentado na Conferência AMFORHT para América Latina, realizada em outubro de 2004, na cidade de natal (Rio Grande do Norte, Brasil). Busca explicitar uma experiência desenvolvida pelo Curso de Turismo da Universidade Federal da Paraíba - UFPB, para ampliar as possibilidades de estreitamento entre ensino e prática no decorrer do processo de formação dos futuros bacharéis em turismo.

Fundado na noção de estimular o desenvolvimento de pesquisas na área de turismo e sua relação com as problemáticas locais, o projeto de monitoria Turismo e Revitalização: Contribuições de Planejamento e Marketing para o Centro Histórico de João Pessoa estimula os alunos das disciplinas que integram o projeto a refletirem sobre as formas de uso turístico condizentes com as noções básicas de sustentabilidade e que atendam às especificidades locais.

Nesse sentido, para contextualizar essas ações apresenta-se, primeiramente, um panorama sobre as bases que regem as atividades de 
ensino, pesquisa e extensão propostas pelo curso de turismo da UFPB para a formação de seus alunos. Também se evidencia a atual situação do processo de revitalização do Centro Histórico de João Pessoa, escolhido como eixo integrador do projeto, e os vários atores que o engendram, tomando como prioridade a comunidade do Porto do Capim.

Diante do reconhecido dinamismo do setor turístico, o curso procura proporcionar uma consciência crítica aos alunos, desenvolvendo o espírito de aprender e de ser criticamente funcional frente às novas situações que, continuamente, acontecem no setor turístico, sempre intensamente dinâmico. É sob essa égide, portanto, que as atividades propostas e desenvolvidas pelo projeto de monitoria que integram alunos, professores e monitores são enfim apresentadas.

\section{Curso de Turismo da UFPB}

O curso de Graduação em Turismo da Universidade Federal da Paraíba (UFPB) foi implantado em 1998 para atender aos interesses de avanço sócioeconômico da região. Além de assumir o papel de um fórum de integração dos estudos e pesquisas acadêmicos e científicos de diversos departamentos da própria Universidade interessados no desenvolvimento turístico regional, oferece aos jovens da região a oportunidade de graduação numa área bastante promissora da economia, com mercado de trabalho local, regional e mundial em contínua e franca ascensão.

Nos últimos anos, nos diversos setores do estado da Paraíba, as referências ao turismo fizeram-se presentes, ora louvando a eleição da atividade como possível redentora da economia de várias de suas regiões, ora clamando por um projeto de desenvolvimento cujas ações sejam voltadas para o incremento do turismo sustentável como forma de evitar grandes impactos que venham a inviabilizar a própria atividade e degradar a qualidade de vida dos habitantes locais. 
ENDRES, Ana Valéria; CARVALHO, André Luiz Piva de. Projeto de monitoria e revitalização; contribuições de planejamento e marketing para o centro histórico de João Pessoa (Paraíba, Brasil). Revista Brasileira de Pesquisa em Turismo. v.4, n.1, p.76-91, abr. 2010.

ISSN: $1982-6125$

Muitos estudiosos do turismo, tais como BENI (1997), COOPER (2001), CRUZ (2000), LEMOS (1996), RODRIGUES (1997a, 1997b, 1997c), CORIOLANO (1998), CORIOLANO; LIMA (2003) entre outros, têm observado a forma como a atividade vem sendo implementada em diversas regiões do país resultando em características de turismo predatório, apresentando índices de degradação no meio-ambiente e exclusão de atores sociais de práticas tradicionais e da cultura de baixa renda. O desgaste da natureza e a desvalorização da cultura nativa podem ser o resultado de um planejamento mal realizado e de ações implementadas de forma precipitada. Projetos de desenvolvimento turístico, com a instalação de equipamentos que alteram a paisagem natural, sem avaliação constante da relação entre benefícios e prejuízos, desembocam sempre em danos irrecuperáveis para a ecologia e a cultura, bloqueando a sustentação turística do lugar.

Os riscos de um desenvolvimento turístico mal planejado e a aspiração generalizada da comunidade, creditando ao turismo uma das principais soluções para o avanço sócio-econômico do Estado, exigiu que a Universidade Federal da Paraíba, no cumprimento de seu papel histórico e social de atender aos anseios da sociedade que indiretamente a mantém, ofereça, com seu curso de turismo, elementos mais capazes para planejamentos, pesquisas e análises sobre a realidade dos componentes da atividade, do seu potencial como fenômeno e como oferta, no estado da Paraíba.

Juntando os aspectos sociais e econômicos do turismo, o estudo do nosso curso de graduação, no âmbito geral, contempla a formação teórica baseada na interdisciplinaridade como objeto de profundas reflexões sobre o fenômeno através das inter-relações geográficas, sociais, educacionais, éticas, culturais e econômicas, permeadas pelas questões de planejamento com vistas à maximização dos efeitos positivos que a atividade pode oferecer e também pela minoração dos prováveis efeitos negativos que o turismo produz sobre as sociedades, tais como a aceleração do consumo, perda de identidade local, exclusão social, alteração das paisagens e degradação ambiental, entre outros. 
Nossa preocupação em relação ao profissional que estamos preparando é a de dotá-lo de uma formação em nível superior com embasamento técnico para trabalhar em planejamento, organização e execução das mais diversas atividades do setor, proporcionando-Ihe, ainda, através do estudo teórico, reflexivo e crítico, uma profunda consciência social, crítica e cidadã, tornandoo um agente eficaz em defesa da preservação do meio-ambiente e do homem da terra e, ao mesmo tempo, resistir às ameaças de degradação de patrimônios ecológicos, históricos e culturais propiciadas pelo seu uso indevido.

Assim, nos preocupamos com as possibilidades da adequação contínua de resultados à dinâmica da realidade, acreditando que a capacidade de inovação encontra-se em razão direta com a acumulação permanente de conhecimentos, habilidades e profissionalismo.

O processo de formação acadêmica procura investir no treinamento de técnicas acompanhado de forte conteúdo humanista que possibilite ao profissional aprender a trabalhar com conceitos, categorias e sistemas políticos, econômicos, sociológicos entre outros, procurando tratar com um grande número de dados no seu cotidiano, contatar pessoas, se relacionar com as mais discrepantes realidades, seja no escritório, em atividade de pesquisa, em viagens de lazer ou de trabalho.

Capacitamos nossos alunos para transmitir conhecimentos do turismo, tanto como fenômeno como produto, ensinando-Ihes as ciências e técnicas que embasam a teoria da atividade turística como fenômeno social de massa e como atividade econômica; organizar empresas e planificar políticas para o setor; prestar consultorias a pequenas empresas; fornecer orientação para o desenvolvimento de empreendimentos em locais com vocação turística, sempre com extensão para programas de envolvimento e participação da comunidade e exigindo o mínimo de custos sociais, econômicos e ambientais.

Atualmente, o curso de turismo da UFPB desenvolve várias pesquisas voltadas, principalmente, para temas cujos objetos sejam a realidade regional inerente ao turismo, trabalhos de extensão junto às comunidades locais como, por exemplo, os projetos "Turismo, meio ambiente e educação: uma proposta 
para o Colégio Agrícola de Bananeiras", "Planejamento participativo e comunicação: contribuições para o desenvolvimento turístico de Mataraca - PB" e "Desenvolvimento da atividade turística na comunidade da Penha", além de registrar a realização de eventos, como o "I ECOTUR - Encontro Regional de Ecoturismo e Turismo de Aventura" e o "Verão 2002 - Turismo com Cultura".

Todas essas atividades atendem à metodologia de também ensinar o turismo na prática, nos espaços sócio-geográficos onde se processam seus fenômenos. Há um vasto campo informativo à disposição, que possibilitam orientar nosso curso para que seja uma graduação moderna e avançada, de forte caráter humanista.

Todas as atividades projetadas pelo curso nesses seis anos são bastante positivas, entretanto, através do projeto de monitoria, procuramos ampliar as pesquisas de professores de diversas áreas que, agora, poderão contribuir melhor para a adequada formação teórica e prática de alunos, atendendo a parâmetros educacionais que preconizam uma formação mais completa possível, alinhando a técnica, o "saber fazer", com a ciência e o embasamento cultural necessários.

Porém, antes de abrir as discussões sobre o projeto de monitoria em si, faz-se necessário descortinar o contexto real no qual está inserido, margeado pelo processo de transformações por que passa o Centro Histórico de João Pessoa atualmente e, mais especificamente, para além da restauração em andamento, discutir as possibilidades de inserção da comunidade do Porto do Capim dentro do processo de revitalização em curso, pois entendemos que as atividades turísticas não devem ser vivenciadas apenas pelo turista, mas também pelo homem da terra, que ainda deve ter o turismo como fonte geradora de empregos e riquezas para a comunidade.

\section{Eixo Integrador: Centro Histórico de João Pessoa e Comunidade do Porto do Capim}


O mundo atual de feição pluralista, multipolar, favorecendo maior intercomunicação entre os indivíduos aponta, na visão de muitos especialistas, mega-tendências como prosperidade econômica, triunfo do individualismo e aceleração da comunicação entre os povos. Tais fatos, ao se tornarem fatores impulsionadores do turismo mundial, exigem entendimento das transformações que estão acontecendo na sociedade, com o objetivo de prever impactos geradores de crescentes violências causadas pela persistência no uso de técnicas indevidas de organização e utilização dos recursos turísticos, que podem, ao se expandir, ameaçar o futuro dessa atividade.

Por outro lado, com o acelerado desenvolvimento tecnológico, turistas mais exigentes e desafios ecológicos e sociais têm forçado a desmitificação das posturas perigosamente contraditórias, tanto dos "economicistas" que vêem o turismo como grande gerador de lucros, como daqueles que o concebem como fator incontestável de harmonia universal, estando ambas isoladas das preocupações com as crescentes perdas de bens materiais e culturais que o aumento desordenado do fluxo de turistas normalmente imprime, contribuindo para a deterioração da qualidade de vida dos habitantes locais e criando dificuldades para a qualificação do lugar como produto turístico.

O reconhecimento da situação descrita, marcada pelo avanço do crescimento da competitividade em relação à atividade turística, passa a requerer o incremento progressivo do nível de informação da população que, de acordo com seu grau de conscientização da importância do turismo como instrumento de crescimento econômico, geração de empregos, melhoria da qualidade de vida e preservação do meio ambiente natural, histórico e cultural, se manifesta de forma variada, ora como ponto de resistência, ora de apoio para a definição ou implementação de políticas de turismo. Nesse sentido, para a elaboração ou conservação de um cenário turístico, há que se investir em programas de desenvolvimento da sensibilização, conscientização e integração da comunidade para motivar sua participação cada vez mais responsável no desenvolvimento do turismo regional, garantindo a criação de uma imagem positiva do lugar. 
ENDRES, Ana Valéria; CARVALHO, André Luiz Piva de. Projeto de monitoria e revitalização; contribuições de planejamento e marketing para o centro histórico de João Pessoa (Paraíba, Brasil). Revista Brasileira de Pesquisa em Turismo. v.4, n.1, p.76-91, abr. 2010.

ISSN: $1982-6125$

Nesse sentido, os atuais processos de revitalização dos centros históricos de diversas capitais brasileiras fornecem subsídios para o desenvolvimento turístico da região, considerando que a atividade deve ser incrementada em função do desenvolvimento sustentável no nível de internacionalização. E em João Pessoa o cenário não seria diferente.

João Pessoa, capital da Paraíba, é a terceira capital mais antiga do Brasil. Dona de uma riqueza histórica e cultural excepcional, a cidade vem sendo alvo de várias intervenções com o objetivo de preservar e conservar seu rico patrimônio. Em 1987, por meio de um convênio entre o Governo do Brasil (Ministério da Cultura - Minc, e do Instituto do Patrimônio Histórico e Artístico Nacional - IPHAN), o Governo Espanhol (Agencia Española de Cooperación Internacional - AECI) o Governo do Estado da Paraíba (Secretaria de Educação e Cultura) e a Prefeitura Municipal de João Pessoa, a capital paraibana foi inserida no Programa de Preservação do Patrimônio Ibero-Americano, que é mantido pela AECI em diversos países da América Latina. A partir dessa parceria começou a ser implantado o Projeto de Revitalização do Centro Histórico de João Pessoa, cujos principais objetivos são as ações que englobem a recuperação e revitalização do Centro Histórico e a qualificação e formação mútua dos membros da equipe do Projeto, com vista à criação de técnicos qualificados e experimentados na revitalização do patrimônio. A primeira etapa do Projeto de Revitalização do Centro Histórico de João Pessoa foi desenvolvida entre os anos de 1989 e 2002. Neste período foram realizadas mais de 15 restaurações, entre edifícios e áreas de lazer.

Além das restaurações já realizadas nos principais edifícios históricos concentrados no centro da capital, as futuras ações governamentais se orientam na proposta de revitalização do Centro Histórico, e tem, como alvo principal, a área denominada Porto do Capim.

A comunidade do Porto do Capim é formada por aproximadamente 870 habitantes e, além das dificuldades intrínsecas às comunidades de baixa renda, tem seu espaço público usado de forma desordenada, o que contraria sua vocação turístico-cultural, transformando a área num espaço degradado. De 
acordo com dados da Comissão do Centro Histórico, a área do Porto do Capim hoje abriga ruínas abandonadas ou parcialmente ocupadas por oficinas mecânicas e lojas de autopeças.

A renda média mensal da comunidade é de um salário mínimo, e a maior parte da sua população em idade ativa, em torno de 38,46\%, encontrava-se desempregada, sobrevivendo de serviços ocasionais. Possuem grau de escolaridade baixo, com $71,43 \%$ da população sem o ensino fundamental completo, e ainda com uma taxa de 24,24\% de analfabetos (COELHO, 2004).

De acordo com o trabalho realizado por Coelho (2004), que discute o envolvimento e grau de participação da comunidade no processo de revitalização em curso, hoje a comunidade está mais consciente da importância que o lugar onde habitam tem para a cidade de João Pessoa. Atualmente, $45 \%$ dos moradores sabem que o Porto do Capim tem grande importância histórica, enquanto que em 2001, apenas 3\% sabiam que o Porto do Capim é considerado o nascedouro da capital paraibana.

Essa mesma amostragem apresenta também que o turismo incipiente no Centro Histórico sempre foi bem aceito. Em 2001, cerca de 90\% dos entrevistados gostariam que fosse implantada a atividade turística na região, pois acreditavam que isso traria emprego e renda para a comunidade. Em 2003 esse número aumentou mais 3\%. Dentre os entrevistados em 2003, aproximadamente $20 \%$ acredita estar preparado para receber bem o turista no Porto do Capim.

Apesar do projeto de revitalização ter sido iniciado em 1989, ainda não houve ações eficazes que conseguissem proporcionar uma justaposição do uso desse espaço urbano, com o uso comercial, habitacional, histórico, de lazer e contemplação, em prol do fluxo contínuo de pessoas ao local, a exemplo de outros espaços históricos revitalizados. Não obstante, Coelho (2004) verificou que a comunidade encontra-se mais participativa nos eventos que acontecem no Centro Histórico, pois além de servir como mão-de-obra, os moradores instalam barracas para venda de bebida, comida e artesanato, aumentando a 
fonte de renda familiar em períodos sazonais, como também participam da programação cultural.

Diante da realidade do Centro Histórico de João Pessoa e da comunidade do Porto do Capim, as ações propostas pelo projeto de monitoria acreditam que as formas de uso desse espaço, baseadas na atividade turística, devem abrir, indubitavelmente, possibilidades de inserção desse grupo social que, até então, ainda se encontra marginalizado do processo de participação das ações de revitalização da área.

\section{Projeto de Monitoria "Turismo e Revitalização: Contribuições de Planejamento e Marketing para o Centro Histórico de João Pessoa"}

Estudos como os de Vieira (2003), Zancheti, S. M.; Marinho, G.; Milet, V (1995), e Barbosa (2001) comprovam que a existência de uma vizinhança imediata a monumentos de valor histórico e artístico requer medidas que a façam fazer parte dos mesmos, não só por ser essa a população que interage cotidianamente com o bem histórico, mas principalmente por que, na medida em que um monumento atrai a atenção de um visitante, aumentará a demanda de comerciantes interessados nos decorrentes lucros desse processo, mudando o fluxo de vida onde se encontra a atração histórica.

De modo que tais medidas devem prever, além dos canais de participação no planejamento, as possibilidades de inserção econômica da comunidade no local revitalizado. Em suma, é criar estratégias que possam possibilitar o desenvolvimento de práticas turísticas que não agridam seus modos de vida, que valorizem o seu meio ambiente e a cultura local, com vistas a manter e proporcionar o seu bem estar.

Diante das ameaças ao patrimônio cultural e ambiental da região e da ausência de estudos, pesquisas e planejamentos que vislumbrem especificamente a atividade turística, resta ao curso de turismo realizar um trabalho mais profundo e racional, não permitindo que a necessidade de soluções rápidas para o turismo regional, diante da idéia de "muito tempo já 
ENDRES, Ana Valéria; CARVALHO, André Luiz Piva de. Projeto de monitoria e revitalização; contribuições de planejamento e marketing para o centro histórico de João Pessoa (Paraíba, Brasil). Revista Brasileira de Pesquisa em Turismo. v.4, n.1, p.76-91, abr. 2010.

ISSN: $1982-6125$

perdido", impeça um trabalho cauteloso e analítico que descubra o melhor caminho para o turismo no local.

É preciso observar que a carência de estudos específicos sobre a atividade turística pode suscitar riscos de um desenvolvimento turístico mal planejado. Nesse sentido, as contribuições do projeto de monitoria se materializam através das práticas inerentes as disciplinas com elementos mais capazes para planejamentos, pesquisas e análises sobre a realidade dos componentes da atividade, do seu potencial como fenômeno e como oferta frente a esse espaço extremamente singular e ímpar para a Paraíba: o Centro Histórico de João Pessoa.

O projeto de monitoria "Turismo e revitalização: contribuições de planejamento e marketing para o Centro Histórico de João Pessoa" tem como base a idéia da indissociabilidade entre ensino e pesquisa, no qual a monitoria não deve proporcionar ao aluno monitor somente uma experiência de ensino, como planejar aulas, selecionar textos, dominar diferentes técnicas de ensino, conduzir uma discussão em sala de aula, orientar a elaboração de trabalhos, entre outras, mas também, uma experiência na produção de novos conhecimentos, isto é, de pesquisa. Assim, o projeto é concebido de forma a propiciar ao monitor, além de formação teórica, formação prática, através do exercício contínuo de reflexão sobre a realidade a ser transformada pela atividade turística.

Aos monitores, bolsistas e voluntários, o projeto propicia treinamento e atividades de ensino e pesquisa através da orientação na preparação e execução das atividades desenvolvidas em sala de aula, bem como das atividades extraclasse; na organização e orientação de leituras específicas de cada disciplina que integram o projeto; no acompanhamento de sua participação nas atividades de extensão promovidas pelo Curso através do Laboratório de Turismo; além da orientação na produção dos relatórios e artigos científicos sobre as atividades desenvolvidas no Centro Histórico.

Em termos acadêmicos, a realização da monitoria, tanto para os monitores como para os demais alunos envolvidos, é importante para 
ENDRES, Ana Valéria; CARVALHO, André Luiz Piva de. Projeto de monitoria e revitalização; contribuições de planejamento e marketing para o centro histórico de João Pessoa (Paraíba, Brasil). Revista Brasileira de Pesquisa em Turismo. v.4, n.1, p.76-91, abr. 2010.

ISSN: $1982-6125$

proporcionar a estes o desenvolvimento de um senso crítico sobre a relação entre turismo e desenvolvimento, que ultrapasse o discurso oficial e predominante em nossa sociedade onde o turismo é sempre bom, haja vista que é papel do curso estimular no quadro discente a realização de atividades que busquem ampliar a relação desenvolvimento e atividade turística com bases locais, além de proporcionar ao aluno uma visão sistêmica do turismo e suas interfaces com outras disciplinas.

Dentro desse contexto, as disciplinas da grade curricular do curso que proporcionam uma discussão mais direcionada às necessidades do Centro Histórico são "Teoria e Técnica do Turismo" (60h / Cr 04); "Planejamento e Organização do Turismo I" (60h / Cr 04); "Marketing Turístico" (60h / Cr 04) e "Turismo e Cultura Popular" (60h / Cr 04).

A escolha desses componentes curriculares se justifica por serem tais disciplinas detentoras de conteúdos específicos que dão suporte aos aprofundamentos necessários para atender a essas premissas, além de serem as disciplinas "Marketing Turístico" e "Planejamento e Organização do Turismo" os alicerces para das habilitações propostas pelo curso de turismo. Tal escolha ratifica a constatação prática de que planejamento e marketing do turismo possuem conteúdos programáticos complementares, propiciando estudos aprofundados sobre a área em questão.

Haja vista a importância da área alvo do projeto, as disciplinas "Teoria e Técnica do Turismo" e "Turismo e Cultura Popular" não poderiam deixar de dar a sua contribuição, considerando ser a primeira a base para o processo de planejamento turístico, e a segunda o aprofundamento das questões culturais tão necessárias para a solidez de futuras ações.

As quatro disciplinas envolvidas agregam aproximadamente oitenta alunos em diversas atividades. A primeira ação conjunta foi realizada no final do mês de junho e início de julho de 2004, onde, com a colaboração dos integrantes da Comissão do Centro Histórico, o guia do Largo de São Frei Pedro Gonçalves, do padre Francisco e da líder comunitária do Porto do Capim, houve a visitação das turmas ao local com intuito de aproximar os alunos da 
ENDRES, Ana Valéria; CARVALHO, André Luiz Piva de. Projeto de monitoria e revitalização; contribuições de planejamento e marketing para o centro histórico de João Pessoa (Paraíba, Brasil). Revista Brasileira de Pesquisa em Turismo. v.4, n.1, p.76-91, abr. 2010.

ISSN: $1982-6125$

realidade da comunidade do Porto do Capim e sua relação com o Centro Histórico. Nessas atividades, além das informações gerais sobre o local, foram realizadas, em função de cada disciplina, orientações sobre como cada uma poderia contribuir com trabalhos inerentes aos seus conteúdos.

À disciplina "Turismo e Cultura Popular" coube o papel de encontrar traços da cultura popular no Porto do Capim a fim de identificar o perfil cultural da comunidade, além de realizar um projeto para o "Encontro Turismo com Cultura Popular no Porto do Capim", bem como a publicação das discussões. $\mathrm{Na}$ visita técnica foram identificadas atuais manifestações populares da Comunidade, como o grupo de percussão Latatá e o grupo de forró Gosto de Capim, formados por crianças da comunidade a partir das oficinas realizadas pelo Projeto Folia Cidadã, da Associação Folia de Rua. A quadrilha junina da comunidade, que em 2004 ficou em segundo lugar no festival de Quadrilhas Juninas de João Pessoa. Além disso, houve a identificação sobre um grupo de Lapinha que existia na comunidade mas que está desativado desde 2002.

Para o fechamento do semestre, cada grupo indicou três representantes de cada segmento identificado na pesquisa para proferir uma palestra, ou, nas palavras da professora da disciplina, uma "conversa informal" com os alunos do curso de turismo da UFPB, em seminários realizados pelos grupos. Quatro temas foram idealizados: "Narrativas populares no Porto do Capim", "Entretenimento e Lazer no Porto do Capim", "As ONG's e a Cultura Popular", "O Rio Sanhauá e o Porto do Capim".

$\mathrm{Na}$ disciplina "Planejamento e Organização do Turismo", que enfoca o exercício de elaboração de projetos de estruturação turística de pequena escala, foram definidos cinco projetos para estruturar turisticamente espaços sub-aproveitados em três áreas distintas do Centro Histórico: dois projetos para as dependências da Igreja de São Frei Pedro Gonçalves - SFPG, um para alguns ambientes do Hotel Globo, e outros dois no trapiche utilizado pela comunidade do Porto do Capim para pesca artesanal, coleta de crustáceos e passeios. A proposta está condicionada pelas possibilidades de serem exeqüíveis e mantidas pela comunidade do Porto do Capim com o auxílio da 
Comissão do Centro Histórico, responsável pelo Hotel Globo e do Padre Francisco, responsável pela Igreja de São Frei Pedro Gonçalves.

A metodologia proposta para a confecção dos projetos remete, primeiramente, a um estudo comum entre os mesmos, no qual é feita uma análise do mercado local aonde irão se implantar os projetos, a fim de identificar suas deficiências e potencialidades, e um estudo sobre a oferta e demanda local, através da análise dos concorrentes diretos e indiretos a fim de avaliar os serviços oferecidos, taxa de ocupação ou visitação, composição da demanda e concluir quanto ao desempenho do empreendimento concorrente.

Busca-se, nesse sentido, transformar pontos negativos do concorrente em aspectos positivos ao empreendimento proposto que possam garantir sua viabilidade. Nesta etapa dos projetos, a disciplina "Marketing Turístico" possui papel fundamental, considerando o conteúdo programático específico ao planejamento mercadológico dos projetos de estruturação em questão.

Considerando as carências em estudos específicos sobre a relação entre os moradores do Porto e a atividade turística, a disciplina "Teoria e Técnica do Turismo" desenvolveu levantamentos sócio-econômicos com a comunidade, além de projetar possibilidades futuras de trabalhos de extensão através de oficinas de capacitação profissional para os moradores interessados. Importante ressaltar que já houve outras iniciativas para a realização de oficinas de capacitação na comunidade, como guias de turismo, artesanato, entre outros. Entretanto, pela ausência de espaços específicos para dar suporte aos produtos desenvolvidos, as oficinas tornaram-se inócuas como possibilidades de renda para a comunidade.

Apesar de iniciado em junho de 2004, é possível perceber, com as atividades já realizadas, que tal experiência contribui efetivamente para a formação dos alunos no tocante às questões técnicas, à maneira e a forma de como fazer. Além de - e principalmente - criar nos alunos envolvidos um senso de responsabilidade frente aos estudos e propostas apresentados. Assim, o êxito na excelência dos planos e projetos, estratégias de desenvolvimento e dos serviços turísticos ofertados tem sua grande garantia na qualidade 
humana, derivada de boa formação técnica e humanista, por meio de várias ações, formais e informais, e de uma atividade responsável no trabalho em todos os níveis.

\section{Conclusões preliminares}

De forma conclusiva, a importância do projeto de monitoria "Turismo e revitalização: contribuições de planejamento e marketing para o Centro Histórico de João Pessoa" passa pelo entendimento da urgência de ações voltadas para a formação, qualificação e atualização dos alunos do curso de turismo da UFPB para que estes respondam com competência aos desafios do setor. Em função disso, as propostas do presente projeto contribuem para a formação do futuro bacharel em turismo, para que este possa melhor atuar, especificamente, nas áreas de magistério e consultoria ; instituições públicas e culturais; geração de bancos de dados para o turismo; execução, administração e gerenciamento de projetos e empresas turísticas; entre outras.

Neste sentido, a formação técnico-humanista que o curso de turismo projeta, através da monitoria, visa preparar o aluno para ser um profissional consciente e responsável na defesa do patrimônio cultural e ambiental, assumindo o papel de agente do desenvolvimento sustentável do turismo regional, sempre a favor da população local, que jamais deve ser excluída dos processos de desenvolvimento do turismo, pois entendemos que o curso de turismo da UFPB tem como compromisso direcionar os estudos para a formação de recursos humanos com forte embasamento cultural e humanístico, estimular e despertar a preocupação com a pesquisa e a investigação e, em conseqüência, preparar profissionais para novas tecnologias, novos equipamentos e novos materiais.

\section{REFERÊNCIAS}


BARBOSA, Y. M. O despertar do turismo: um olhar crítico sobre os nãolugares. São Paulo: Aleph, 2001.

BENI, Mário Carlos. Análise estrutural do turismo. São Paulo: SENAC, 1997.

COELHO, J. G. O desenvolvimento turístico do Centro Histórico de João Pessoa e a participação da comunidade local: o caso do Porto do Capim. João Pessoa: Curso de Graduação em Turismo/UFPB, 2004. (Trabalho de Conclusão de Curso).

COOPER Chris (org.) Turismo: princípios e prática. Porto Alegre: Bookman, 2001.

CORIOLANO, Luzia N. M. Do local ao global: o turismo litorâneo cearense. Campinas, SP: Papirus, 1998.

CORIOLANO, Luzia N. M.; LIMA, Luiz C. Turismo comunitário e responsabilidade socioambienatal. Fortaleza: EDUECE, 2003.

CRUZ, Rita de Cássia. Política de turismo e território. São Paulo: Contexto, 2000.

HALL, Michael. Planejamento turístico. São Paulo: Contexto, 2001.

LEMOS, Amália. (org.) Turismo: impactos socioambientais. São Paulo: HUCITEC, 1996.

RIBEIRO, E. et all. Guia prático para elaboração de projetos turísticos. Botucatu, SP: Igral, 2002.

RODRIGUES, Adir B. (org.) Turismo, modernidade e globalização. São Paulo: HUCITEC, 1997.

1997.

. (b) Turismo e ambiente: reflexões e propostas. São Paulo: HUCITEC,

. (c) Turismo: desenvolvimento local. São Paulo: HUCITEC, 1997.

VIEIRA, Natália Miranda (org.). Práticas preservacionaistas contemporâneas: valor cultural X valor econômico. Salvador: s.r., mai. 2002. Seção Artigos. Disponível em: <http://carlota.cesar.org.br/arqbr>. Acesso em: 19 nov. 2003. ZANCHETI, S. M.; MARINHO, G.; MILET, V. (org). Estratégias de Intervenção em Áreas Históricas. Recife, PE: MDU/UFPE, 1995.

Artigo recebido em dezembro de 2009.

Aprovado para publicação em fevereiro de 2010. 